\title{
Impact of Long-term Soft Relining of Mandibular Complete Dentures on Brain Activity and Cognitive Function of Elderly Patients
}

\author{
Eman Mostafa Ahmed Ibraheem ${ }^{1}$, Hoda Gaafar Hassan Hammad²* \\ ${ }^{1}$ Department of Removable Prosthodontics, National Research Centre, Cairo, Egypt; ${ }^{2}$ Department of Dental Biomaterials, \\ Batterjee Medical College, Jeddah, Saudi Arabia
}

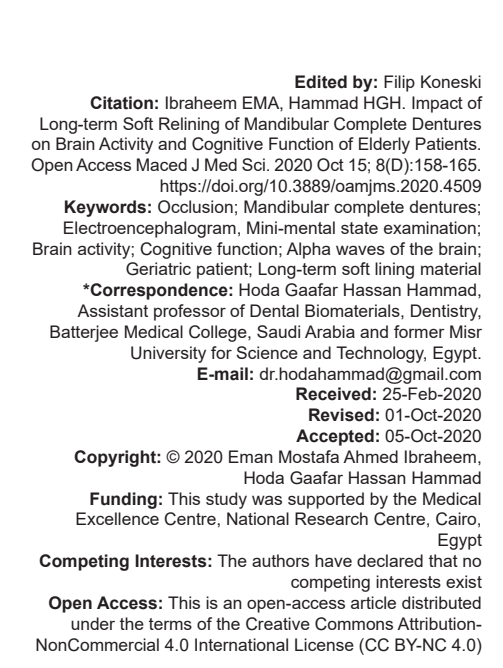

\section{Abstract}

BACKGROUND: Stability and retention of mandibular complete denture are a chronic complaint in elderly patients and it may have potential effect on dementia.

AIM: The study was conducted to evaluate the impact of the long-term soft liner (LTSL) for mandibular dentures on brain activity and cognitive function of completely edentulous elderly patients.

PATIENTS AND METHODS: Thirty elderly completely edentulous denture wearer patients were selected to participate in the study. Patient's brain activity and cognitive function were investigated before and after the relining of the mandibular complete dentures with an LTSL material. Patient's brain activities were investigated by electroencephalograms, while patient's cognitive functions were evaluated by the aid of mini-mental state examinations.

RESULTS: Statistical analysis of obtained results revealed a significant difference in patient's brain activity as well as a cognitive function before and after the relining of the mandibular complete dentures.

CONCLUSIONS: Long-term soft-lined mandibular dentures seemed having an impact on brain activity and cognitive function for elderly completely edentulous denture wearers.

\section{Introduction}

Physiologically, human teeth loss is associated with alveolar bone resorption that functionally increases by age. Consequently, the decreased ridge height jeopardizes the retention and stability of complete dentures, with special consideration for the mandibular prosthesis [1], [2], [3]. Recently, the prevalence of edentulism is more concentrated in old patients and dental practitioners may frequently face challenges associated with providing prosthodontic care for these completely edentulous patients [4], [5]. Elderly completely edentulous patients seem frustrated from retention and stability of the lower denture and reduced masticatory efficiency [6], [7].

Many attempts were tried to improve the retention of mandibular complete denture weather by clinical tips, materials, oral surgeries, or dental implants [2], [8]. In addition, hard and soft denture liners, denture adhesives, and implant-supported dentures were various modalities to enhance lower denture retention [7], [9]. Permanent and temporary denture lining materials are polymeric substances dispersed on the fitting surfaces of dentures to increase the adaptation of dentures to occlusal stress-bearing oral tissues. Being in intimate contact with patient oral mucosa, denture liners must be nontoxic, non-irritant and hindering all fungal and bacterial colonization [10], [11]. Hard denture liners are longterm resin-based polymers, usually manufactured from polymethyl methacrylate (PMMA) [11]. Short-term and long-term soft, resilient denture liners are categorized as plasticized acrylic resins or silicone elastomeric materials that are used with partial and complete removable dentures to homogeneously distribute functional stresses on oral denture-bearing mucosa [11], [12].

Actually, human brain is controlling not only all body functions, such as physical movement, heart activity, speech, but also thinking, memory, and emotional perception. Brain activity can be measured with electroencephalography (EEG) as a neurologic examination method. The principle of the EEG is to capture the electric brain potential through multiple electrodes placed on the patient scalp over a determined period of time [13], [14]. Brainwaves are produced from the synchronization of electrical pulses from masses of neurons that communicate with each other. The unit of measurement of brainwave frequency is Hertz (i.e., Hz; cycles per second). In 
addition, brainwaves are divided into fast, moderate, and slow delineating bands [14], [15], [16]

Major human brain wave is infra-low waves $(<0.5 \mathrm{~Hz}$, they are generating with deep meditation and during dreamless sleep), delta waves (0.5-3 $\mathrm{Hz}$, they are a source of empathy and they suspend the external awareness), theta waves (4-8 Hz, they improve human creativity, intuition, and natural feeling), alpha waves (9-12 Hz, they help overall calmness, mental coordination, integration of mind/ body, learning, and alertness), beta waves (13$39 \mathrm{~Hz}$, they control normal consciousness and cognitive tasks), and gamma waves $(40-100 \mathrm{~Hz}$, they simultaneously process information from various brain zones) [14], [16]. Alpha wave frequency, ranging between beta and theta waves; therefore, it can bridge the gap between the conscious thinking and the subconscious mind [14].

Mini-mental state examination (MMSE) is considered as one of the most sensitive cognitive tests for discrimination between normal persons and patients affected by dementia and cognitive impairment [17], [18].

Recently, patients impaired brain activity and cognitive function represent one of the most frequent neurological, geriatric symptoms, which deteriorates their quality of life and arouses their familial and social burden. Early detection as well as proper management of risk factors seems essential to prevent cognitive morbidity. Many studies reported a correlation between tooth loss and cognitive feebleness with or without dementia of communitydwelling elderly patients [18], [19].

Subsequently, this study was conducted to assess the effect of long-term soft liner (LTSL) for lower dentures on cognitive function and brain activity of completely edentulous old patients with the aid of the MMSE and EEG, respectively.

The purpose of the study was to investigate the impact of long-term soft relined mandibular dentures on brain activity and cognitive function of elderly completely edentulous patients.

\section{Patients and Methods}

All study patients were informed about the clinical steps of the study and written approval consent was filled and signed by each participating patient.

\section{Materials}

The materials used in the study were:

- $\quad$ LTSL material: MUCOPREN ${ }^{\circledR}$ SOFT.
Kettenbach GmbH and Co. KG, Germany.

Heat cured PMMA Lucitone-199 (DENTSPLY

Trubyte, Int. Inc., York, PA, USA).

\section{Patients selection}

Thirty elderly male patients were selected for the study from the Medical Excellence Centre, National Research Centre, Cairo, Egypt. All patients had previously constructed and worn complete dentures that were made up of heat-cured acrylic resin (polymethyl methacrylate; PMMA) for not $<2$ years with persistent mandibular dentures retention and stability problems.

EEG and MMSE were performed for all study patients before denture relining and 3 months after relining with the LTSL of mandibular complete dentures.

\section{Patient inclusion/exclusion criteria}

- $\quad$ Thirty completely edentulous male patients aging from 60 to 70 years were selected (mean age $\approx 65$ years)

- $\quad$ Patients were non-smokers.

- Selected patients had no history of brain diseases such as cerebral infarction and they had never been diagnosed with dementia such as Alzheimer's disease.

Patients having a history of any temporomandibular joint disorders, psychiatric illness, or neuromuscular disorders such as bruxism or severe clenching were absolutely excluded from the study.

- Patients were Angle's Class I skeletal malocclusion, and they had well-developed maxillary and mandibular alveolar ridges lined with firm mucoperiosteal.

Thorough intra-oral and extra-oral examinations, panoramic radiograph, and maxillary and mandibular diagnostic casts were performed for all study patients.

Instructions were given to all patients that at bedtime, they should get their upper and lower complete dentures out, clean the denture fitting surfaces and massage the oral tissues with a toothbrush and keep dentures in a cup containing water overnight.

\section{Prosthodontic management}

- $\quad$ All selected patients had previously constructed and used conventional heat-cured acrylic resin complete dentures for not $<2$ years with a history of retention and stability problems of mandibular dentures [20].

- Mandibular complete dentures had received the essential prosthetic adjustments aiming to achieve optimal retention, maximum stability, and the necessary occlusal contacts.

EEG and MMSE assessments were performed 
for all patients.

- Afterword, the mandibular dentures were relined with LTSL materials to improve retention of mandibular dentures.

\section{Relining technique (direct - abrasion method)}

- $\quad$ Relining of mandibular dentures was performed by reducing one $\mathrm{mm}$ of the denture fitting surfaces and borders to make a right-angled border.

- $\quad$ Manipulating the LTSL material according to manufacturer instruction.

- $\quad$ Afterword, apply two separate layers of Mucopren adhesive upon the vestibular surface of the mandibular denture and allow each layer to dry for about $40 \mathrm{~s}$.

- $\quad$ Even thickness of LTSL was distributed over the mandibular denture-fitting surface using the supplied syringe.

- $\quad$ Then, the lower denture was inserted and molded in patient mouths, while biting in centric occlusion with the opposing maxillary complete dentures.

- $\quad$ After proper setting of LTSL material, excess material was trimmed and the mandibular complete dentures were finished and polished. Post-insertion care was confirmed to all participating patients.

- Patients were comfortably using their relined mandibular complete dentures for at least 3 months before the next EEG and MMSE assessments.

\section{Evaluation methods}

Brain activity and cognitive function were assessed using EEG and MMSE questionnaire, respectively.

\section{EEG assessment}

EEG was done for all patients who were enrolled in the study to evaluate brain activity before and after use of relined mandibular complete dentures. All patients EEGs were accomplished in a neurology unit (ATES MEDICA Device S.R.L. has finalized a company fusion with EB Neuro S.p.A., Colognola ai Colli [Verona] Italy; model OPTIPLEX 755, installed operating system Win. XP SP3, Acquisition system).

Before each patient record, the parameters of EEG equipment were calibrated as follows: $0.3 \mathrm{~s}$ time constant, $3.0 \mathrm{~cm} / \mathrm{s}$ drawing speed, and $50 \mathrm{~Hz}$ filter. During EEG recording, participants were comfortably seating at rest position with closed eyes. According to the international 10-20 system, the pasteless bridge electrodes were arranged on patient scalps.

In addition, a 21-channel scalp EEG was accomplished while placing reference electrodes on both patient earlobes (Figure 1). Data of EEG were recorded for $20 \mathrm{~min}$; after confirming the stability of detected EEG activities from all applied electrodes. Furthermore, bipolar and referential EEG montages were applied. Patients EEG tracing were interpreted to detect alpha $(\alpha)$ waves $(8-12 \mathrm{~Hz})$ before and 3 months after wearing of relined mandibular dentures. Monitored alpha $(\alpha)$ waves were prominent occipitally in 01 and O2 channels

\section{MMSE}

A set of MMSE questionnaire (11 questions with maximum scoring of 30) was given to each patient to assess the cognitive function before and 3 months after wearing the relined mandibular dentures with LTSL [21], [22].

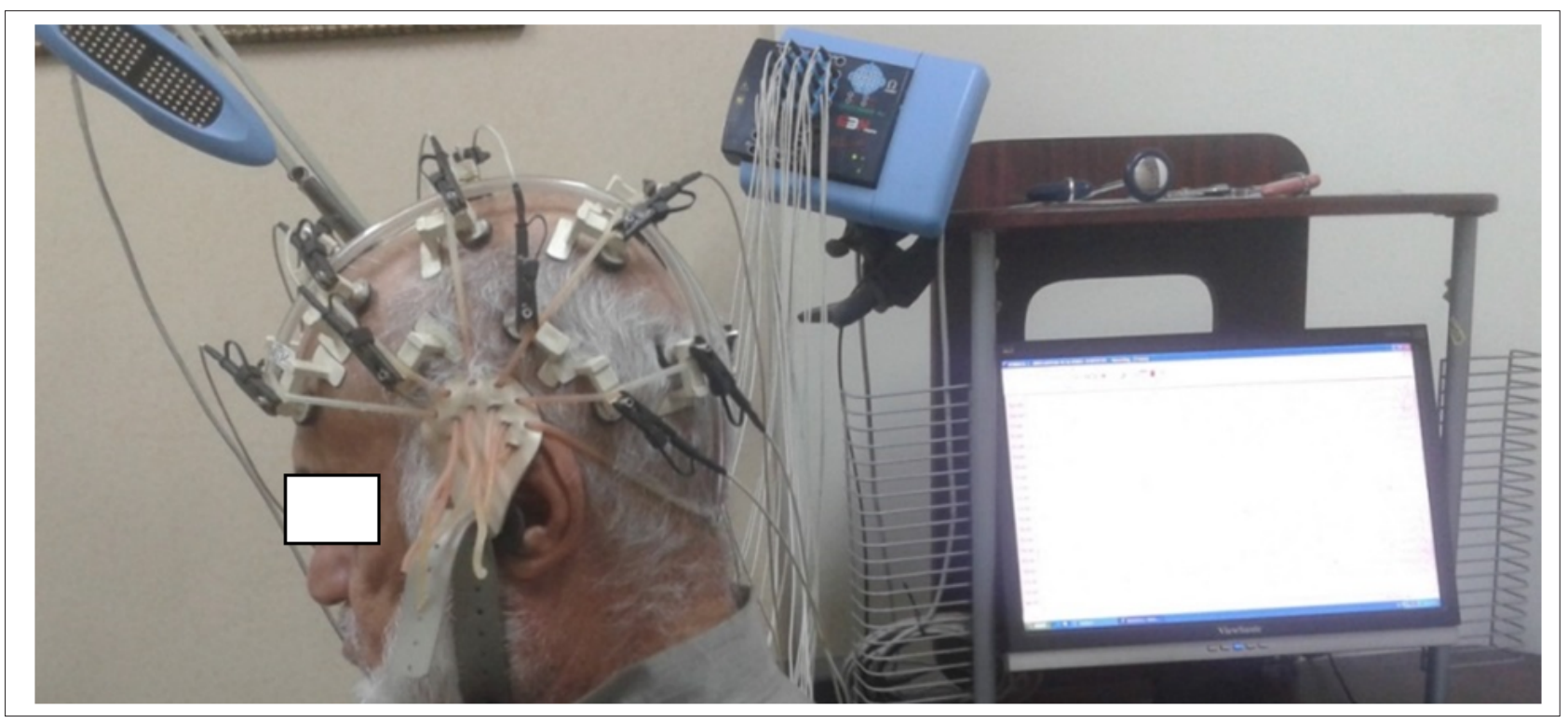

Figure 1: A photograph showing electroencephalogram patient assessment 


\section{Statistical analysis}

Paired t-test was used to compare the brain activity and cognitive function pre- and post-relining of mandibular complete dentures with an LTSL material. Statistical analysis was performed using SPSS $20^{\circledR 1}$, Graph Pad Prism ${ }^{\circledR 2}$, and Microsoft Excel $2016^{3}$ and significant level set at $p \leq 0.05$. Obtained data were represented as means (M) and standard deviation (SD).

\section{Results}

At the beginning of the study, EEG was recorded for each study patient (30 participants) before relining of the mandibular denture with the LTSL material to monitor the alpha $(\alpha)$ brain waves. After the wear of lower denture relined with LTSL for 3 months, EEG again was examined for each patient. The frequency of alpha brain wave before and after the relining of mandibular denture with the LTSL material was collected and was presented as means (M) and standard deviation (SD).

Table 1: EEG monitored alpha ( $\alpha$ ) brain wave frequency (mean $\pm \mathrm{SD}$ in $\mathrm{Hz}$ ) before and after relining of mandibular denture with the LTSL material

\begin{tabular}{llll}
\hline & Number of patients & $\mathrm{M} \pm \mathrm{SD}($ in $\mathrm{Hz})$ & p-value \\
\hline Before & 30 & $9.6 \pm 0.5477$ & $0.005^{\star *}$ \\
After & 30 & $11 \pm 0.70711$ & \\
\hline M: Mean, SD: Standard deviation, p: Probability level. ${ }^{* *}$ Significant difference. LTSL: Long-term soft liner,
\end{tabular}

EEG: Electroencephalography.

The calculated obtained mean and standard deviation before and after relining was $9.6 \pm 0.5477$ and $11 \pm$ 0.70711 , respectively, as shown in Table 1 and Figure 2. A paired t-test was implemented to evaluate the significance level at $p \leq 0.05$, and it revealed a significant difference in patient $\alpha$-brain wave frequencies before and after denture relining as $p<0.05$, as presented in Table 1.

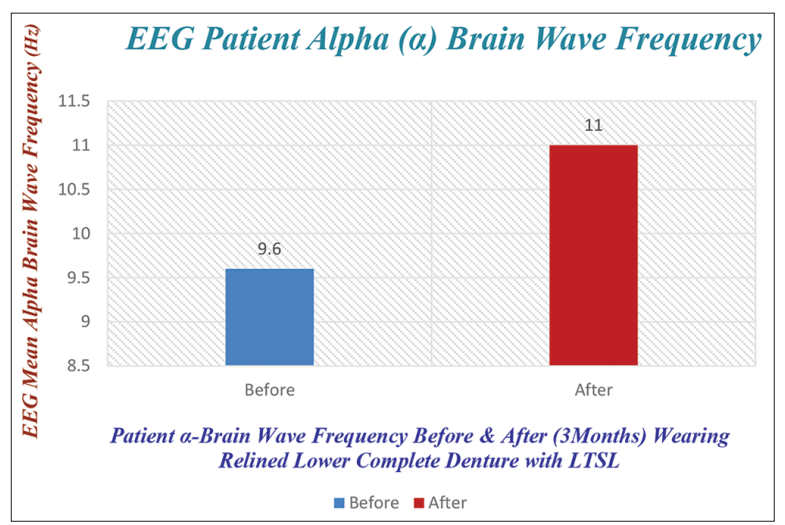

Figure 2: Bar charts comparing patient $\alpha$-brain wave frequency (Mean $\pm S D$ in $\mathrm{Hz}$ ) before and after (3 months) wearing of lower complete denture relining with $L T S L$

1 Statistical Package for Social Science, IBM, USA.

2 Graph Pad Technologies, USA

3 Microsoft Co-operation, USA.
The cognitive function of the study patient was assessed with a standardized MMSE questionnaire that had a total score of 30 , before and after mandibular complete denture relining (Figure 3).

Accordingly, all patient MMSE data were gathered and calculated as (mean $\pm S D$ ). The obtained results before and after mandibular complete denture relining were $16.9 \pm 3.96$ and $19.2 \pm 2.62$, respectively, as shown in Table 2 and Figure 4. A paired t-test was performed for evaluation of significance level at $p \leq 0.05$, which revealed a significant difference in patient cognitive function before and after use of relined lower complete denture as $p<0.05$, as presented in Table 2 .

Table 2: Patient brain cognitive function evaluation with a standardized mini-mental state examination questionnaire $(M \pm S D)$ used before and after relining of lower complete denture

\begin{tabular}{llll}
\hline & Number of patients & $\mathrm{M} \pm \mathrm{SD}$ & $\mathrm{p}$-value \\
\hline Before & 30 & $16.9 \pm 3.96$ & $0.009^{* *}$ \\
After & 30 & $19.2 \pm 2.62$ & \\
\hline M: Mean, SD: Standard deviation, p: Probability level. ${ }^{* *}$ Significant difference.
\end{tabular}

Consequently, the applied paired t-test for both $\alpha$-brain activity and cognitive brain function evaluation, before and after (3 months) of LTSL lower complete denture relining, revealed a significant difference level at $p \leq 0.05$, as presented in Tables 1 and 2, Figures 2 and 4.

\section{Discussion}

Indeed, during the function, the complete dentures are moving relative to the underlying alveolar bone. Denture instability had the potential of traumatizing the supporting oral tissues. Thus, throughout complete denture techniques and philosophies, the achievement of maximum retention and stability appeared to be a major objective of prosthodontics. Consequently, denture stability usually presented the distinguishing factor between the success and failure of a removable prosthesis [23], [24].

Unfortunately, unstable dentures might reduce the patient maximum bite forces because of weaken jaw muscles and the produced disuse atrophy. During mastication, that patient situation presented a vicious cycle as the resultant masticatory muscle weakness might further contribute towards a decrease in maximum biting forces. In addition, that clinical scenario was more obvious in patients using unstable conventional mandibular dentures for long term [8], [24], [25].

Various attempts were devised to improve mandibular denture stability and retention, including modification upon impression surface, polished surface, mandibular residual ridge, and occlusal surface [23], [24]. Furthermore, LTSL materials were administered to denture fitting surfaces to improve stability and retention. The short-term soft denture liners maintained their 
STANDARDIZED MINI-MENTAL STATE EXAMINATION (SMMSE)

\begin{tabular}{|c|c|c|c|}
\hline & QUESTION & TIME ALLOWED & SCORE \\
\hline \multirow[t]{5}{*}{1} & a. What year is this? & 10 seconds & 11 \\
\hline & b. Which season is this? & 10 seconds & h \\
\hline & c. What month is this? & 10 seconds & 1 \\
\hline & d. What is today's date? & 10 seconds & 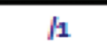 \\
\hline & e. What day of the week is this? & 10 seconds & / \\
\hline \multirow[t]{5}{*}{2} & a. What country are we in? & 10 seconds & 11 \\
\hline & b. What province are we in? & 10 seconds & $M$ \\
\hline & c. What city/town are we in? & 10 seconds & 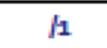 \\
\hline & $\begin{array}{l}\text { d. IN HOME-What is the street address of this house? } \\
\text { IN FACIITY - What is the name of this building? }\end{array}$ & 10 seconds & h \\
\hline & e. IN HOME- What room are we in? IN FACILITY - What floor are we on? & 10 seconds & 1 \\
\hline 3 & $\begin{array}{l}\text { SAY: I am going to name three objects. When I am finished, I want you to repeat } \\
\text { them. Remember what they are because I am going to ask you to name them again in } \\
\text { a few minutes. Say the following words slowly at 1-second intervals - ball/ carl man }\end{array}$ & 20 seconds & /3 \\
\hline 4 & Spell the word WORLD. Now spell it backwards. & 30 seconds & 15 \\
\hline 5 & Now what were the three objects I asked you to remember? & 10 seconds & 13 \\
\hline 6 & SHOW wristwatch. ASK: What is this called? & 10 seconds & 1 \\
\hline 7 & SHOW pencil. ASK: What is this called? & 10 seconds & h \\
\hline 8 & SAY: I would like you to repeat this phrase after me: No ifs, ands or buts. & 10 seconds & 11 \\
\hline 9 & $\begin{array}{l}\text { SAY: Read the words on the page and then do what it says. Then hand the person } \\
\text { the sheet with CLOSE YOUR EYES on it. If the subject reads and does not close their } \\
\text { eyes, repeat up to three times. Score only if subject closes eyes }\end{array}$ & 10 seconds & $/ 1$ \\
\hline 10 & $\begin{array}{l}\text { HAND the person a pencil and paper. SAY: Write any complete sentence on that } \\
\text { piece of paper. (Note: The sentence must make sense. Ignore spelling errors) }\end{array}$ & 30 seconds & h \\
\hline 11 & $\begin{array}{l}\text { PLACE design, eraser and pencil in front of the person. SAY: Copy this design please. } \\
\text { Allow multiple tries. Wait until person is finished and hands it back. Score only for } \\
\text { correctly copied diagram with a } 4 \text {-sided figure between two } 5 \text {-sided figures. }\end{array}$ & 1 minute & 11 \\
\hline 12 & $\begin{array}{l}\text { ASK the person if he is right or left-handed. Take a piece of paper and hold it up in } \\
\text { front of the person. SAY: Take this paper in your right/left hand (whichever is non- } \\
\text { dominant), fold the paper in half once with both hands and put the paper down on } \\
\text { the floor. Score } 1 \text { point for each instruction executed correctly. } \\
\text { Takes paper correctly in hand } \\
\text { Folds it in half } \\
\text { Puts it on the floor }\end{array}$ & 30 seconds & $\begin{array}{l}1 \\
1 \\
1\end{array}$ \\
\hline & TOTAL TEST SCORE & & 130 \\
\hline
\end{tabular}

Note: This fool is provided for use in British Columbia with permission by Dr. William Molloy. This questionnaire should not be further modiffed or reproduced without the written consent of Dr. D. William Molloy.

Provided by the Alzheimer's Drug Therapy Initiative for physician use.

Figure 3: Standardized mini-mental state examination questionnaire of 30 total score, used before and after relining of lower complete denture

resilience for more than 1 month, while the long-term was recommended for use for up to 1 year [11], [26].

The chairside LTSL resilient liner selected in the study was elastic self-curing silicone. The LTSL showed an excellent permanent elastic adhesion to the vestibular mandibular acrylic denture surfaces (smooth, shiny silicone/acrylic interfacial surface). Moreover, LTSL provided relieved critical areas of patient oral mucosa 


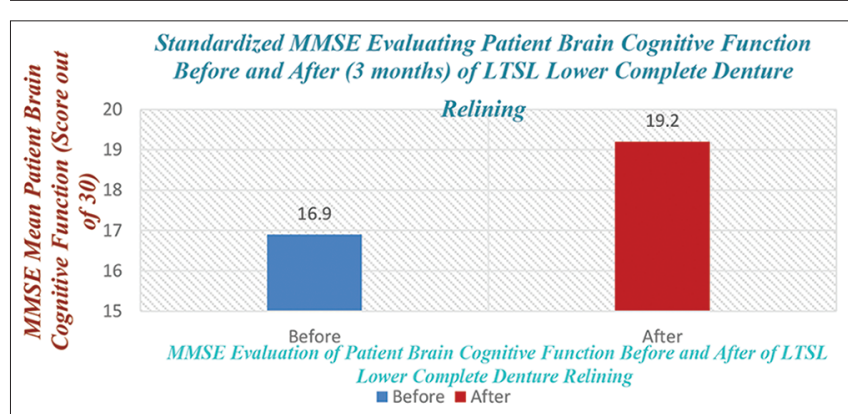

Figure 4: Bar charts comparing MMSE evaluating patient brain cognitive function before and after ( 3 months) of LTSL lower complete denture relining

and ensured high intraoral comfortability. The smooth LTSL hydrophobic silicone surface impeded bacterial settling, prevented infections upon the lower denturebearing area, and guaranteed stable retained hygienic denture for a long-term period. Those lower dentures (LTSL) relining aimed to potentially alleviate the trauma associated with wearing of complete dentures as well as to improve poor retention of mandibular dentures, which was in coincidence with Ahmed et al., 2015 [27] and Toporowska et al., 2019 [28]. In addition, the used LTSL showed promising long service life with high tear strength and good stability of the denture-supporting area. Those findings were in agreement with Kreve and Dos Reis, 2019, who reported that the hardness of resilient siliconebased denture liners was more stable and durable than that of resilient acrylic resin-based denture liners [11], [28].

Physiologically, human brain wave impulses change according to actions and feelings. Hence, when low brain wave frequencies are dominating, individual may feel sluggish, tired, or dreamy, while higher ones predominate when he perceives hyper-alert, tense, or wired [15], [16]. Alpha brain waves are assisting overall calmness, mental coordination, alertness, learning, and mind/body integration; therefore, this $\alpha$-frequency range cross over the gap between conscious thinking and the subconscious mind. In other words, $\alpha$-frequency ranges between theta and beta $(\beta)$. It helps us calm down when necessary and promotes feelings of deep relaxation. At stress, a very small alpha $(\alpha)$ potential and an excessive beta $(\beta)$ activity give rise to a phenomenon called "Alpha Blocking;" as $\beta$ brain waves block out $\alpha$ brain waves production [13], [14].

Evidently, aging seems a risk factor for the deterioration of both sensory and motor human functions [29], [30]. Marked tooth loss in geriatric patients reduces the oral function that may adversely affect brain activity. Recently, many researches confirm that prosthodontic rehabilitation appears to have an obvious positive impact on perceived brain activity, general health, and life quality [30], [31]. Obtained patient brain alpha wave results from EEG showed significant improvement in brain functions that were in coincidence with Kusdhany et al., 2016 [17] and Mursid et al., 2017 [32].
MME was successfully used to evaluate the improvement of human cognitive function for complete denture wearers with prosthetic treatment that had improved not only patient masticatory efficiency but also had activated the cerebral functions. Those findings were in agreement with many studies; Fereshtehnejad et al. 2018 [33] found that elderly patients with a higher rate of MMSE declination showed a rapid reduction in the rate of dental care consultations. Patient chewing after wearing dentures was reported to increase activation of cognitive function [33].

Accordingly, LTSL used for the relining of mandibular complete dentures for elderly patients enhanced denture occlusal contact areas and patient force of occlusion that consequently improved brain activity and cognitive function [17]; therefore, in that study, patients did the MMSE after mandibular denture relining by 3 months.

\section{Conclusions}

Within the limitations of this study on soft-lined mandibular complete dentures, the followings can be complemented:

1. LTSL for mandibular dentures with appropriate denture construction seems comfortable materials that alleviate the trauma associated with complete dentures in addition to improving denture stability and retention.

2. Long-term elastic relining with LTSL had improved their mastication and denture function for a long period.

3. Alpha brain wave frequencies increase with mastication, indicating activation of brain function and prevention of dementia and Alzheimer.

4. Cognitive function was highly improved with regular comfortable masticatory function.

\section{Recommendations}

Future researches with longer follow-up periods and permanent denture relining materials are recommended to investigate its impact on brain activity and cognitive functions for elderly patients.

\section{Authors' Contributions}

Both authors equally contributed to this study. The authors revised and approved the final manuscript. 


\section{References}

1. Misch CE. Contemporary Implant Dentistry. $3^{\text {rd }}$ ed. Amsterdam: Elsevier, Mosby; 2008. p. 61, 293.

2. Ibraheem EM, Hammad HG, El-Sisy AM. Comparing marginal bone height changes around immediately and delayed implantretained mandibular overdentures in controlled diabetic patients: A randomized clinical study. Bull Natl Res Centre. 2019;43:198. https://doi.org/10.1186/s42269-019-0228-1

3. Doundoulakis JH, Eckert SE, Lindquist CC, Jeffcoat MK. The implant-supported overdenture as an alternative to the complete mandibular denture. J Am Dent Assoc. 2003;134:1455-8. https:// doi.org/10.14219/jada.archive.2003.0073

PMid:14664262

4. Patel J, Jablonski RY, Morrow LA. Complete dentures: An update on clinical assessment and management: Part 1. Br Dent J. 2018;225:933-9. https://doi.org/10.1038/sj.bdj.2018.866 PMid:30468182

5. Office for National Statistics. Overview of the UK Population: July 2017. Available from: https://www.ons.gov.uk/releases/ overviewoftheukpopulationjuly2017. [Last accessed on $21 \mathrm{Jul}$ 2017].

6. Jain P, Rathee M. Stability in Mandibular Denture. Treasure Island, FL: Stat Pearls Publishing LLC; 2019.

7. Ibraheem EM, Hammad HG. Effect of commercially available denture adhesives on microhardness of a flexible denture base material. Open Access Maced J Med Sci. 2019;7(5):862-8. https://doi.org/10.3889/oamjms.2019.193

PMid:30962852

8. Pradeep N, Devassy JP, Sreekumar AV. Sublingual crescent extension: A solution for loose lower denture. Case Report. Saint Int Dent J. 2015;1(1):66-8. https://doi. org/10.4103/2454-3160.161822

9. Elmorsy AE, Ibraheem EM, Aboul Ela A, Fahmy A, Nassani MZ. Do flexible acrylic resin lingual flanges improve retention of mandibular complete dentures? J Int Soc Prevent Community Dent. 2015;5(5):365-71. https://doi. org/10.4103/2231-0762.165928

PMid:26539387

10. Atay A, Cetintas VB, Cal E, Kosova B, Kesercioglu A, Guneri P. Cytotoxicity of hard and soft denture lining materials. Dent Mater J. 2012;31(6):1082-6. https://doi.org/10.4012/dmj.2012-209 PMid:23207219

11. Kreve S, Dos Reis A. Denture liners: A systematic review relative to adhesion and mechanical properties. ScientificWorldJournal. 2019;2019:6913080. https://doi.org/10.1155/2019/6913080 PMid:30940994

12. Hashem Ml. Advances in soft denture liners: An update. $J$ Contemp Dent Pract. 2015;16(4):314-8. PMid:26067736

13. Koudelková1 Z, Strmiska M. Introduction to the Identification of Brain Waves Based on their Frequency. MATEC Web of Conferences 210, 05012. International Conference on Circuits, Systems, Communications and Computers; 2018. https://doi. org/10.1051/matecconf/201821005012

14. Das T. Consciousness as a function of brain waves and physical constant conscire. NeuroQuantology. 2017;15(3):1-6. https:// doi.org/10.14704/nq.2017.15.3.1047

15. Brain Works, Train your Mind. Brain Training Excellence Since; 2007. Available from: https://www.brainworksneurotherapy.com/ what-are-brainwaves. [Last accessed on 06 Oct 2020].

16. Berger H. Alpha Brain Waves and Biofeedback Science. Biocybernaut: Alpha Brain Waves, Feedback, Biofeedback Science, Beta, Theta, Delta, EEG; 2002. p. 41. Available from: http://www.biocybernaut.com/tutorial/alpha.html. [Last accessed on 06 Oct 2020].

17. Kusdhany L, Nathanael M, Dyas R, Indrasari M, Masulili $C$ Rahardjo TB, et al. Impact of using denture on cognitive function in the elderly. J Int Dent Med Res 2016;9:286-92. https://doi. org/10.1088/1742-6596/884/1/012084

18. Park H, Suk SH, Cheong JS, Lee HS, Chang H, Do SY, et al. Tooth loss may predict poor cognitive function in community dwelling adults without dementia or stroke: The present project. J Korean Med Sci. 2013;28:1518-21. https://doi.org/10.3346/ jkms.2013.28.10.1518 PMid:24133359

19. Sajid H, Athar Y, Sagheer A, Yazdanie N, Arshad A, Shahid F. Association between tooth loss and oral awareness amongst dentate and partially dentate subjects of Pakistani population. $J$ Int Dent Med Res. 2017;10(3):877-82.

20. Rani I, Shetty J, Reddy V. A comparison of peri-implant strain generated by different types of implant supported prostheses. J Indian Prosthodont Soc. 2017;17:142-8. https://doi. org/10.4103/0972-4052.203195

PMid:28584415

21. Crum RM, Anthony JC, Bassett SS, Folstein MF. Populationbased norms for the mini-mental state examination by age and educational level. J Am Med Assoc 1993;269:2386-91. https:// doi.org/10.1001/jama.269.18.2386

PMid:8479064

22. Folstein MF, Folstein SE, McHugh PR. Mini-mental state: A practical method for grading the cognitive state of patients for the clinician. J Psych Res 1975;12:196-8. https://doi.org/10.1037/ t07757-000

23. Lau M, Amarnath GS, Muddugangadhar BC, Swetha MU, Das KA. Tensile and shear bond strength of hard and soft denture relining materials to the conventional heat cured acrylic denture base resin: An in-vitro study. J Int Oral Health 2014;6(2):55-61. https://doi.org/10.18535/jmscr/v5i12.58 PMid:24876703

24. Wright CR. Evaluation of the factors necessary to develop stability in mandibular dentures. J Prosthet Dent. 1966;92(6):509-18. PMid: 15583554

25. Caloss R, Al-Arab M, Finn RA, Lonergan O, Throckmorton GS. Does long-term use of unstable dentures weaken jaw muscles? J Oral Rehabil. 2010;37(4):256-61. https://doi. org/10.1111/j.1365-2842.2009.02046.x PMid:20050986

26. ELsyad MA, Shaheen NH, Ashmawy TM. Long-term clinical and prosthetic outcomes of soft liner and clip attachments for bar/implant overdentures: A randomized controlled clinical trial. J Oral Rehabil. 2017;44(6):472-80. https://doi.org/10.1111/ joor. 12500 PMid:28258636

27. Ahmed EM, Esmat AM, Hassan HG. Candida albicans colonization on different polymeric denture base materials in controlled type II diabetic patients. J Arab Soc Med Res 2019;14:95-101. https://doi.org/10.4103/jasmr.jasmr_20_19

28. Toporowska AN, Malecka K, Raszewski Z, Wieckiewicz W. Changes in hardness of addition-polymerizing siliconeresilient denture liners after storage in artificial saliva. J Prosthet Dent. 2019;121(2):317-21. https://doi.org/10.1016/j. prosdent.2018.05.002 PMid:30093127

29. Katsoulis J, Nikitovic SG, Spreng S, Neuhaus K, MericskeStern R. Prosthetic rehabilitation and treatment outcome of partially edentulous patients with severe tooth wear: 3-years results. J Dent. 2011;39:662-71. https://doi.org/10.1016/j. jdent.2011.07.008 
PMid:21827819

30. Ikebe K, Matsuda K, Kagawa R, Enoki K, Okada T, Yoshida M, et al. Masticatory performance in older subjects with varying degrees of tooth loss. J Dent. 2012;40(1):71-6. https://doi. org/10.1016/j.jdent.2011.10.007

PMid:22037296

31. Reissmann DR, Schierz O, Szentpétery AG, John MT. Improved perceived general health is observed with prosthodontic treatment. J Dent. 2011;39:326-31. https://doi.org/10.1016/j. jdent.2011.02.003
PMid:21315132

32. Mursid S, Pujnadati CK, Kusdhany LS. Awareness and demand of prosthodontic treatment for tooth loss replacement. J Int Dent Med Res. 2017;10(3):872-6.

33. Fereshtehnejad SM, Garcia-Ptacek S, Religa D, Holmer J, Buhlin K, Eriksdotter M, Sandborgh-Englund G. Dental care utilization in patients with different types of dementia: A longitudinal nationwide study of 58,037 individuals. Alzheimers Dement 2018;14(1):10-9. https://doi.org/10.1016/j jalz.2017.05.004 